\title{
IMPACTO SOCIAL DA PESQUISA EM ENFERMAGEM
}

\author{
Semiramis Melani Melo Rocha* \\ Magali Roseira Boemer*
}

Mario Testa usa a palavra prismático para definir termos ou expressões que não só podem ter muitos significados, como, ao serem pronunciados, permitem múltiplas reflexões, como um prisma reflete a luz em várias direções. (TESTA, 1992).

Quando recebi o convite para falar sobre o impacto social da pesquisa em enfermagem, ocorreu-me a possibilidade das várias interpretações do termo e formas de abordá-lo.

Percebendo que não poderia dar conta da tarefa só, convidei a Profa. Dra. Magali Roseira Boemer para compartilhar a autoria do trabalho e lhe sou muito grata por tê-lo aceito.

Optamos por iniciar marcando nossa posição sobre o que entendemos por ciência. Há várias formas de apreender a realidade. Um quadro de Portinari, retratando os emigrantes das regiões áridas e secas pode despertar em nossa sensibilidade e razão a percepção das formas e dos sofrimentos daqueles seres humanos. Uma música pode evocar um sentimento. As artes são formas de apreender o real, assim como as ciências. É possível obter um conhecimento da realidade a partir de óticas diversas: desde a captação intuitiva e sensível, até sua análise com procedimentos científicos. Alguns destes procedimentos proporcionam resultados tidos como mais verdadeiros do que outros, mas é muito difícil, provavelmente impossível, estabelecer concepções de verdade e comparaçôes com base em critérios comuns devido às diferenças internas de validação de cada método. Procurar aplicar a lógica formal para verificar a validade e confiabilidade de observações em todos os métodos é desastroso pois alguns se propõem a contestar a 16gica formal.

A ciência apresenta a vantagem, frente a outros modos de conhecimento, de assegurar, em certa medida, os resultados obtidos utilizando procedimentos que exigem requisitos rigorosos. Mas o cumprimento desses requisitos nem sempre é efetivo.

Existem diversas maneiras dos cientistas se equivocarem em suas buscas de verdades. Os procedimentos que fazem parte do método da ciência são objeto permanente de debate entre epstemólogos, metodólogos, filosofos e historiadores da ciência. (TESTA, 1992)

- Enfermeira. Professor Associado da Escola de Enfermagem de Ribeirão Preto da Universidade de São Paulo. 
Para a finalidade desta reflexão sobre o impacto social da pesquisa em enfermagem, consideramos como científicos os trabalhos de investigação que apresentam coerência interna e adequação entre os pressupostos, a teoria, o método, o delineamento do objeto, as técnicas e estratégias e a análise dos resultados. Esta proposição, entretanto, não é suficiente para delinearmos nossa concepção de ciência.

A ciência, como problema social, possui uma dupla determinação: a que provém dos conteúdos específicos e concretos próprios do enígma que procura resolver e a procedente do contexto social, que determina sua adequação ou inadequação a tal contexto. A primeira é o que a torna universal e a segunda o que a torna um instrumento útil. A ausência dessa segunda determinação transforma a ciência em cientificismo. (TESTA, 1992) O cientificismo é uma ciência descontextualizada, onde falta o apoio de uma realidade a partir da qual formula seus problemas, métodos, estratégias e resultados. Um mesmo método pode ser ciência em uma certa circunstância e cientificismo em outras. Esta dupla significação é encontrada sempre que nos confrontamos com problemas sociais, isto $\hat{e}$, com fenômenos inseparáveis das muitas maneiras pelas quais uma sociedade é ordenada. Estas questões se refletem nos métodos que são utilizados para abordar os problemas de investigação.

A forma de pór no contexto histórico um objeto de trabalho científico é começar por sua observação tal como se apresenta no mundo real, utilizando-se para tanto as categorias comuns, pensadas habitualmente. $O$ processo de investigação, através do duplo caminho da abstraçáo e da reconstrução conceitual, transformará essas categorias em outras, mais precisas, que levem à compreensão do fenomeno que se analisa. Isto $e$, as categorias iniciais permitem perceber o fenômeno, as finais permitem compreendê-lo. Como decorrência imediata, o método de investigação é uma construção da própria investigação. Não existe uma metodologia separada e independente dos problemas a serem resolvidos. (TESTA, 1992)

"Se a história pode levar a uma ciência verdadeira, uma ciência verdadeira tem que servir para a construção da historia ". (TESTA, 1992, p.55)

Partindo destes pressupostos genéricos, trouxemos para discutir o impacto social da pesquisa em enfermagem algumas questões que consideramos importantes e que têm sido pouco tratadas nos encontros entre pesquisadores em enfermagem dos quais temos participado. Nossa intenção é, modestamente, incitar o debate.

Inicialmente, apresentaremos algumas relações entre o científico e o político na atualidade, fundamentadas em declarações de políticos e cientistas divulgadas na literatura e na imprensa. A seguir, a opinião de um cientista sobre a ciência e a medicina no século XXI. Contextualizando, trouxemos alguns dados sobre o financiamento à pesquisa no Brasil e um breve histórico da pesquisa em enfermagem. Com estas ponderações, esperamos fazer com vocês, ouvintes e eventuais leitores, uma reflexáo sobre o impacto social da pesquisa em enfermagem.

O científico e o político

A pesquisa interessa o Estado, às empresas, à sociedade civil. Moderna- 
mente, está organizada em instituições ligadas ao Estado e/ou à iniciativa privada. Direta ou indiretamente, o Estado moderno destina parte de seu Produto Interno Bruto (PIB) à pesquisa. No Quadro 1 (Anexo 1), temos a porcentagem do PIB destinada à pesquisa por continente e pals, em 1989.

Há várias formas de se avaliar o resultado da pesquisa. Uma delas é a sua capacidade de gerar tecnologia, entendida aqui como uma atividade historicamente em desenvolvimento para a construção de máquinas e outros artefatos, invenção de técnicas e processos, criação e transformação de materiais e organização do trabalho, indo ao encontro de necessidades do homem. (KNELLER, 1980)

No quadro 2 (Anexo 2) temos a apresentação do número de patentes solicitado por país em 1989, como um indicador de sua produção científica. Verificamos que os paises considerados desenvolvidos aplicam financeiramente mais em pesquisas e produzem mais tecnologia.

Há, entretanto, outras formas de avaliação, mais qualitativas que quantitativas. Para Paul FEYERABEND (1991), um filosofo contemporâneo, nos últimos dois séculos as ciências nos gratificaram com seus resultados. Contaram-nos históricas tão ricas e tão fascinantes quanto os mitos que as precederam. Chamaram nossa atenção para eventos comuns como o comportamento de pássaros e peixes e idealizaram uma tecnologia que transformou o mundo. A cada ano surgem novas descobertas e contribuiçóes aos aspectos mais prosaicos da existência humana. Por outro lado, provocaram danos irreparáveis. Culturas antigas e associações tribais, que proporcionavam segurança econômica e satisfação espiritual, foram desfeitas sem serem substitufdas por estruturas compatíveis. Muitos dos chamados problemas do terceiro mundo, tais como fome, doença e falta de habitação, parecem ter sido causados, e não solucionados, pelo contínuo avanço da civilização ocidental.

As questões primordiais enfrentadas pelo homem atualmente são:

1 bilhão de pobres no planeta;

10 milhões de mortes anuais de crianças por doenças inevitáveis;

erosão do solo;

escassez de água;

destruição de florestas tropicais;

aquecimento global;

desaceleração na produtividade agrícola;

destruição da camada de ozônio.

De que forma os dirigentes politicos e os homens de Estado podem encaminhar as questões possibilitando que a ciência seja um fator positivo para a humanidade? Líderes políticos cobram soluções e reflexóes éticas dos cientistas. (POLÍTICOS, 1990) Estas, por sua vez, recusam limites para a liberdade de investigação e atribuem a má utilização dos resultados da ciência ao direcionamento de sua aplicação que tem sido norteada para objetivos muito imediatos, sem considerar e ponderar suas conseqüências a médio e longo prazos. (PESQUISADORES, 1991) 
... " quando realizamos uma pesquisa tentamos estabelecer os contornos da realidade através de uma observação rigorosa e sistemática. O que podemos esperar da pesquisa é exatamente isto: uma base factual de maior confiança e com probabilidades de enganos melhor dimensionados. A pesquisa não vai gerar conclusões ou decisões de política econômica, educacional ou o que seja. O que pode fazer é gerar uma base factual mais confiável a partir da qual estas decisóes possam ser tomadas. O próprio método cientifico impõe limitações com relação dquelas perguntas que podem ser respondidas e dquelas generalizações que podem ser obtidas. diante da multiplicidade de variáveis em ação, a estratégia usual do método cientifico é criar condições de observação onde se reduza o número de variáveis atuando. Por conseguinte, será mais reduzida a possibilidade de uma análise científica quanto maior o número de variáveis que estiver em jogo em uma determinada situação. O poder e o rigor das conclusões cientificas estão inversamente correlacionados com a complexidade do problema examinado. Pessoas em posiçăo de tomar decisões estão particularmente interessadas em situações de elevada complexidade, onde há muitas variáveis em jogo, elevado grau de associação entre variáveis e problemas ds vezes intratáveis de interação ".

Para alguns, as ciências tendem a se fracionar em múltiplas especializações e os cientistas não dão conta dos problemas que englobam as diversas áreas como as questões ambientais, por exemplo. Os políticos devem tomar a decisão de combater os problemas, mas para isso os cientistas devem trazer-lhes uma resposta global.

Nesse debate convém atentar para os limites do poder do homem sobre o homem, manifesto de várias formas de dominação/submissão, quais sejam, o poder das nações economicamente mais desenvolvidas sobre as em desenvolvimento, dos grupos que detém a ciência e o conhecimento sobre àquelas que não têm acesso à educação. É preciso ainda atentar para a responsabilidade que temos em relação ao legado que transmitiremos às gerações futuras.

Urge, portanto, restaurar a primazia da ética.

\section{A ciência e a medicina no século XXI}

Na opinião de Luc MONTAGNIER (1991), professor do Instituto Pasteur, em Paris, e descobridor o vírus da AIDS, as tendências da pesquisa e sua repercussão na saúde no século XXI, podem ser assim sintetizadas:

"O século XX assistiu aos prodigiosos progressos da humanidade em sua luta contra as doenças infecciosas. Pode-se dizer que é em grande parte graças a esses progressos que a população mundial passou de 1.6 bilhão em 1900 para, aproximadamente 6 bilhões em 1990.

As vacinas e os antibióticos permitiram uma redução, ao menos no hemisfério Norte, da mortalidade provocada por tuber- 
culose, difteria, febre tifoide, tétano, raiva, poliomielite, gripe entre outras.

No entanto, essas doenças ainda persistem em regióes tropicais, atingidas também por parasitoses, entre as quais a malária, em primeiro lugar. Subnutrição séria, falta de higiene e de estruturas adequadas são as causas que deverão persistir no século XXI, podendo agravar-se com a explosão demográfica.

Uma nova catástrofe, surgida no início da última década, anuncia a devastação nos países do Terceiro Mundo e, em menor grau nos países do Norte; a AIDS.

Pode-se esperar para antes do ano 2000 o aperfeiçoamento de uma vacina contra a infecção e progressos terapêuticos que permitam retardar e até mesmo estancar a evolução dos soro positivos. Mas, a que preço? Provavelmente suportável pelos países desenvolvidos, contudo, proibitivo para o mundo em desenvolvimento.

Isso conduzirá as populações ricas à duas opções:

- a isolacionista, na qual se deixa o mundo tropico equatorial sofrer essa nova patologia, acrescentando-a às já existentes. Essa opção é contra os valores universalistas do Ocidente, a atual corrente de intercâmbio e abertura mundiais e necessitaria de medidas coercitivas para ser imposta;

- a solidariedade, a única moralmente aceitável, implica enormes sacrifícios financeiros. Sua manutenção dependerá de uma elevação no nível econômico, ocidentalização das economias e redução da explosão demográfica.

Além disso, os países desenvolvidos investem e gastam com outros males: câncer, doenças neurológicas, degenerativas, velhice como doença multifatorial, doenças cardiovasculares, doenças genéticas.

Concluindo, a pesquisa médica vai trazer soluções maravilhosas - mas extremamente caras - para as calamidades que nos afligem. Essa pesquisa conduzirá cada vez mais para terapias preventivas, instituídas antes do surgimento de lesões irreversíveis.

O conjunto dessas técnicas poderá recuar a senilidade e a morte em uns 20 anos no final do século XXI, com conseqüências sociais incalculáveis, mas antes que cheguemos a elas cabe questionar: quem será beneficiado? É claro que não será uma humanidade de 10 bilhōes de indivíduos. A aplicação será desigual, seguindo os níveis de desenvolvimento dos países.

Em um cenário otimista, pode-se imaginar que, graças ao esforço internacional, a subnutrição e as doenças infecciosas e parasitárias regredirão nos países tropicais. Essa regressão deverá ser acompanhada de um controle demográfico absolit to e de uma educação buscando mudar os comportamentos habituais. " 
Este pensar de MONTAGNIER (1991) nos remete ao pensamento de FURTADO (1992) para o qual a superação do subdesenvolvimento não se daria ao impulso das simples forças do mercado, exigindo um projeto político apoiado na mobilização de recursos sociais que permita empreender um trabalho de reconstrução de certas estruturas. O objetivo dessa reconstrução seria remover os entraves à ação criativa do homem, a qual, nas condições do subdesenvolvimento, está caracterizada por anacronismos institucionais e por amarras de dependência externa. $O$ verdadeiro desenvolvimento se dá nos homens e tem importante dimensão política.

Para esse autor, essa mudança de rumo exige que abandonemos muitas ilusões, que exorcizemos os fantasmas de uma modernidade que nos condena a um mimetismo cultural esterelizante. Devemos assumir nossa situação e abrir caminho para o futuro a partir do conhecimento de nossa realidade.

A primeira condição para liberar-se do subdesenvolvimento é escapar da obsessão de reproduzir o perfil daqueles que se auto-intitulam desenvolvidos. É assumir a propria identidade.

\section{O financiamento à pesquisa no Brasil}

A ciência produzida no Brasil, medida em artigos publicados em revistas científicas de circulação internacional, está aproximadamente em $30^{\circ}$ lugar. Significa menos de $0,5 \%$ da produção mundial, de acordo com Rogério MENEGHINI (1991), professor da USP, em entrevista a FOLHA DE S.PAULO.

Uma das possíveis explicações para este desempenho pode ser encontrada no financiamento à pesquisa. Segundo o Prof. Enio CANDOTTI (1992), Presidente da Sociedade Brasileira Para o Progresso da Ciência, de 1985 a 1990 o governo investiu anualmente apenas $0,6 \%$ do PIB, o equivalente a US $\$ 2,2$ bilhões. A verba foi dividida da seguinte maneira:

Secretaria da Ciência e Tecnologia

Embrapa (projetos p/agricultura)

Ministérios militares (projetos espaciais -

Saúde

MEC (universidades)

Programas e comissôes variadas

US\$ 900 milhões

US\$ 300

US\$ 400

US\$ 300

US\$ 200

US\$ 100

Em 1990 a Secretaria recebeu apenas US\$ 600 milhões; em 1991, US\$ 400 e para 1992, estavam previstos US\$ 300 milhões. Até junho de 1992 havia-se recebido 100 milhões de dólares.

Como verificamos, a Secretaria de Ciência e Tecnologia da Presidencia tem suas verbas reduzidas, o que tem comprometido o CNPq, a FINEP, o INPE, INPA, entre outras instituições de pesquisa.

Diante dessa escassez é importante destacar a distribuição das verbas decorrente das diretrizes políticas das instituições de fomento. Nesse sentido, há de se pontuar a declaração do Professor Hélio JAGUARIBE, em julho de 1992, relatando uma primeira discussão no Conselho de Ciência e Tecnologia onde se adotou a idéia, passível de revisões, de concentrar $60 \%$ dos recursos na área de ciências biofísicas e matemáticas, $30 \%$ nas sociais e $10 \%$ na área de humanidades. 
Houve decisáo de, gradualmente, estimular a pesquisa incentivada e reduzir a pesquisa livre, fixar prioridades para a pesquisa induzida, a qual deteria maioria dos recursos - $80 \%$ contra $20 \%$ para a livre.

Tal diretriz pode ser contraposta a uma argumentação do Professor Antonio Cesar Perri de Carvalho, Pro-Reitor de Graduação da UNESP, para quem os projetos de pesquisa atrelados a necessidades maiores da sociedade que atendam a um planejamento governamental são pertinentes, porém, os projetos espontâneos ou o atendimento de "balcão " pelas agências de fomento são indispensáveis para se garantir a iniciativa individual, a criatividade e a própria pesquisa.

O desenvolvimento científico e tecnológico tambem tem sido propiciado por fundações estaduais, destacando-se as fundações dos estados da região sul e sudeste e, em particular, a Fundação de Amparo à Pesquisa do Estado de São Paulo (FAPESP).

\section{A pesquisa em enfermagem}

Cabe agora uma reflexão no que tange à pesquisa em enfermagem. Um exame parcial da literatura nacional permite evidenciar um consenso entre autores de que há um percurso histórico na pesquisa em enfermagem, cujo marco é a primeira defesa de tese de cátedra na década de 60.

Nesse percurso tem sido relevante o trabalho da ABEn:

- em levantamentos empíricos sobre recursos e necessidades de enfermagem no Brasil;

- criando o Centro de Estudos e Pesquisas em Enfermagem (CEPEN);

- promovendo regularmente os Seminários Nacionais de Pesquisa em

Enfermagem;

- promovendo encontros referentes à pesquisa e a pós-graduação;

- organizando um banco de dados, documentado nos catálogos de Pesquisa e Pesquisadores em Enfermagem no Brasil, com publicação periodica.

Estes eventos e publicações têm possibilitado análise quantitativas e qualitativas sobre o conhecimento que vem sendo gerado através da pesquisa.

A literatura consultada ressalta ainda o papel da pós-graduação no desenvolvimento da investigação em enfermagem, iniciada na década de 70 com os cursos de mestrado; em 1980, a criação do Doutorado em Enfermagem vem fortalecer as atividades, consolidando-se as linhas de pesquisa. Abre espaço, ainda, para uma diversificação de abordagens teórico-metodologicas que contemplem as especificidades e a amplitude da área.

As análises a que nos referimos acima vêm pontuando algumas características da produção científica em enfermagem: predominam as produções individuais, realizadas por docentes; no que se refere a temática, o foco desloca-se de áreas técnicas específicas para estudos mais amplos com explicitação do referencial teórico-metodológico.

Acompanhando este caminhar de uma visão mais tecnicista para uma mais abrangente e crítica, houve também um deslocamento da área biologica para as ciências humanas e sociais. 
Alguns autores manifestam uma preocupação com o estabelecimento de prioridades ao encontro da real necessidade de conhecimento na área, de forma que esta possa consolidar-se enquanto uma profissão com um corpo de conhecimentos especificos que the possibilite exercer seu papel na sociedade. Reconhecem a necessidade do trabalho em equipe em pesquisa para o fortalecimento de grupos afins, o que pode proporcionar maiores oportunidades de subsídios dos órgãos financiadores. No entender de ANGERAMI; MENDES (1989), a significância do probleña dependerá do potencial de contribuição que ele poderá trazer ao corpo de conhecimentos da enfermagem. Sua importância depende:

- do benefício que o conhecimento produzido poderá trazer a pacientes,

a enfermeiros, à comunidade ou sociedade;

- da aplicabilidade de seus resultados a prática;

- da relevância teórica dos resultados;

- da possibilidade do estudo vir a colaborar para a transformação da prática;

- do impacto que seus resultados possam produzir.

De todo o exposto, parece-nos caber nesse momento uma reflexão no que se refere ao nosso ver a pesquisa em enfermagem e as possibilidades da mesma produzir impactos.

A busca pelo conhecimento se mostra como vital para a consolidação de uma área de saber. Essa busca visa a construção, através de caminhos metodologicos coerentes, de melhores condições de existência para o homem. isto se nos apresenta como a mola propulsora para a busca de conhecimento.

Entretanto, como expusemos na relação entre o científico e o político, tal pensar não encontra ressonância quando analisamos a realidade concreta.

Poderíamos então nos perguntar em que proporção os trabalhos de enfermagem têm contribuído para a solução ou amenização daqueles problemas mencionados. Certamente que muitos dos resultados advindos das pesquisas em enfermagem podem estar contribuindo de uma forma mais efetiva para a compreensão dos problemas de saúde. O que nos parece, contudo, é que falta uma articulação institucional entre esta área do conhecimento - a enfermagem - e as grandes áreas que dominam a ciência.

É consenso na comunidade científica que a pesquisa avança em grandes projetos temáticos ou nos chamados projetos integrados que reúnam pesquisadores multidisciplinares, em diferentes fases de formação, propiciando um trabalho comum, enfocado sob diversos prismas, interligando diferentes instituições.

Os argumentos desse ver a pesquias apontam para as possibilidades de se chegar a resultados que, por contemplar diversas faces de um problema de investigação, são mais visíveis a médio prazo e podem trazer maiores repercussões sociais.

Conforme já pudemos expor, as análises da produção científica em enfermagem apontam para uma iniciativa individual que, só recentemente, vem evidenciando a formação de equipes, núcleos ou grupos de pesquisadores. Em 1981, em Brasília, ocorreu a primeira classificação das áreas e linhas de pesquisa, referencial que tem sido utilizado nas tentativas de análise da produção.

Essa classificação vem se mostrando insuficiente para contemplar a produção atual. Entretanto, apesar dessa "insuficiência ", os enfermeiros estão tendo dificuldades para propor uma outra organização temática que aglutine a 
produção existente. As tentativas de aglutinação sob o referencial existente apontam dispersões e variações que não tendem para convergências. Além disso, uma determinada categoria classificatória aplicada a trabalhos realizados há dez anos, não tem possibilitado agrupar atualmente, temáticas com o mesmo conteúdo. Assim, sob a categoria ensino de enfermagem, encontrávamos trabalhos que se referiam, em sua maioria ao ensino de graduação em enfermagem; hoje, dentro deste tema diversificam-se em educação continuada, em especialidades (ensino em enfermagem psiquiátrica), entre outros. Assistência de Enfermagem tratava exclusivamente da assistência prestada pelo enfermeiro; hoje, inclue trabalhos onde se discute o fato de várias categorias profissionais prestarem assistência, estudam métodos de assistência, auto-cuidado e avaliação. Não resta dúvida que isto vem ocorrendo em resposta às questões suscitadas pela prática.

Verifica-se também que a produção de conhecimento é incorporada aos currículos de graduação, como é o caso da metodologia de assistencia de enfermagem, ministrada em várias disciplinas. Entretanto, parece haver um descompasso entre três etapas: produção do conhecimento, ensino e prática; quando o conhecimento é incorporado ao currículo, a prática já está exigindo novas soluções teóricas para apreender novas realidades ou aprofundar transformações.

A definição de linhas de pesquisa ainda é uma questão aberta nesta área de conhecimento. Para os pesquisadores em enfermagem, a linha vem se definindo na própria prática da pesquisa e consiste numa reunião de pesquisadores, em várias fases de formação, com alguma infraestrutura, geralmente um banco de dados, cujo centro da aglutinação pode ser o objeto de investigação, como no caso do aleitamento materno, saúde da mulher, ou a fundamentação teórica, como no caso da fenomenologia. Pode ainda, $o$ instrumento ou a tecnologia utilizada para a investigação constituir-se em um foco de aglutinação de pesquisadores, com diferentes objetos de investigação e diferentes embasamentos teóricos.

Todos estes fatos se refletem na imagem externa da área. Numa entrevista informal, o Diretor Científico de uma agência de fomento à pesquisa, em 1991, quando procurado por um grupo de pesquisadores em enfermagem para se pronunciar sobre os problemas e dificuldades da pesquisa nessa área e sua relação com outras áreas de investigação, fez uma avaliação dos pontos mais críticos.

Um primeiro ponto destacado foi em relação à divulgação do conhecimento produzido. A área possue alguns periódicos nacionais, ligados à escolas ou instituições, que publicam trabalhos muito bons ao lado de outros, de menor qualidade. Seria oportuno que a enfermagem envidasse esforços no sentido de ter um periódico de ampla divulgação, com um conselho editorial rigoroso, publicando resultados de investigação mais conclusivos.

A seguir, referiu-se à promoção de eventos. A área promove eventos atomizados, isto é, vários eventos de nível local, regional, sobre temáticas muito específicas; à promoção da pesquisa interessam eventos de grande porte, sobre temáticas mais abrangentes.

Referindo-se à participação de eventos no exterior, disse não ser interessante promover a ida de pesquisadores para divulgar pequenos trabalhos, poster, temas livres, devendo-se priorizar participações mais efetivas, na qualidade de convidados com apresentação de resultados expressivos de uma produção mais consolidada. Atentou ainda para outros aspectos do intercâmbio entre pesquisadores, como a relevância de trazer professores visitantes, com bons currículos e 
boa produção em pesquisa, para implementar linhas de investigação, aqui permanecendo por um período mínimo de três meses. Em contrapartida, há de se promover a demanda da enfermagem para pós-doutorado no exterior.

Retomando o problema do financiamento à pesquisa, reconhecemos que dependemos de órgãos estatais, sendo nossa principal fonte de fomento o Conselho Nacional de Desenvolvimento Científico e Tecnológico $(\mathrm{CNPq})$ e, indiretamente, a Coordenação de Aperfeiçoamento de Pessoal de Nível Superior (CAPES). Cabe portanto uma séria discussão sobre suas diretrizes políticas e uma tomada de posição da área sobre pesquisa induzida, incentivada ou pesquisa livre, isto é projetos espontâneos.

Desta forma, o que nos apresenta neste momento histórico é a necessidade de uma organização das lideranças da enfermagem em torno de uma diretriz politica que permita confluências da pesquisa, engajando-a aos grandes projetos que atendam as necessidades de nossa realidade social, nossas condições epidemiologicas, produzindo um conhecimento contextualizado.

\section{REFERENCIAS BIBLIOGRÁFICAS}

ANGERAMI, E. L. S.: MENDES, I. C. Marco teơrico das investigações em enfermagem: sua relação com as teorias de enfermagem. Rev. Gaúcha Enf., v.10, n.2, p.20-4, 1989.

CANDOTTI, E. Folha de S.Paulo, 26 jul 1992, cad. 6, p.5.

CASTRO, C. M. A prática de pesquisa. São Paulo, MacGraw Hill do Brasil, 1977.

FEYERABEND, P. "Maravilhas" da tecnologia sustentam mito do progresso. Folha de S.Paulo, São Paulo, 27 dez. 1991, cad.5, p. 11.

FURTADO, C. Brasil: a construção interrompida. Rio de Janeiro, Paz e Terra, 1992.

JAGUARIBE, H. Folha de S.Paulo, São Paulo, 26 jul. 1992, cad.6, p.4.

KNELLER, G. F. A ciência como atividade humana. Rio de Janeiro, Zahar, 1980.

MENEGHINI, R. Folha de S.Paulo, São Paulo, 26 jul. 1992. cad.6, p.6.

MONTAGNIER, L. Medicina do futuro vai ser privilégio de países ricos. Folha de S.Paulo, São Paulo, 27 dez. 1991, cad.5, p.14-15.

PESQUISADORES revidam com radicalização e ceticismo. Folha de S.Paulo, São Paulo, 27 dez. 1991, cad.5, p.5.

POLfTICOS cobram soluçōes e reflexōes éticas dos cientistas. Folha de S.Paulo, São Paulo, 27 dez 1991, cad.5, p.4.

TESTA, M. Pensar em satide. Porto Alegre, Artes Médicas, 1992.

\section{BIBLIOGRAFIA CONSULTADA}

ALMEIDA, M. C. P. et al. A produção do conhecimento na pós-graduação em enfermagem no Brasil. Congresso Brasileiro de Enfermagem. XXXIII Anais. Manaus, ABEn, 1981, p.119-26.

ANGERAMI, E. L. S. Prioridade de investigação em enfermagem. Rev. Paul. Enf. 5(2):47-53, 1985.

ANGERAMI, E. L. S. \& MENDES, I. A. C. O saber, a saúde e a investigação em enfermagem. $R$. Gaúcha Enferm, Porto Alegre, 10(1):28-33, 1989.

1989.

Marco teórico das investigaçōes em enfermagem. R. Gaúcha Enfenn, Porto Alegre, 10(2),

AVALIAÇĀo \& PERSPECTIVAS. Seminário sobre ensino de Pós-graduação e pesquisa de Enfermagem. Brasilia, CNPq, 23 a 26, mar. 1982. 
MENDES, I. A. \& TREVISAN, M. A. Acerca da utilização do método científico nas pesquisas em enfermagem. Revista Brasileira de Enfermagem. 36(1):13-9, 1983.

ROCHA, S. M. M. \& SILVA, G. B. Linhas filos 6 ficas e ideologicas na pesquisa em enfermagem. Rev. Brasileira de Enfermagem. 40(4):214-21, 1987.

VIEIRA, T. T. Produção cientifica em enfermagem no Brasil: 1960-1979. Salvador, Escola de Enfermagem da Universidade Federal da Bahia, 1980. (Tese Professor-Titular).

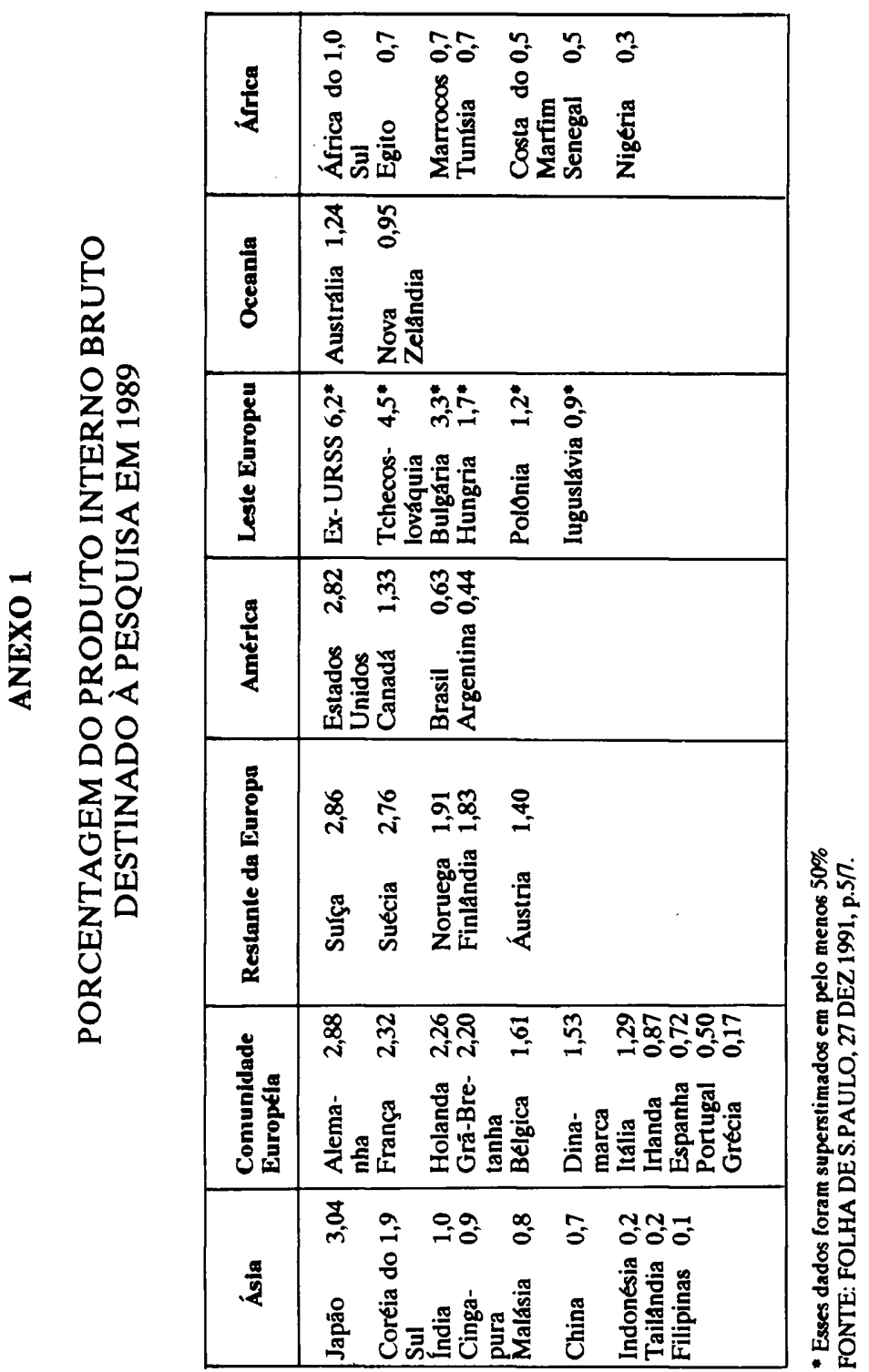

